\title{
SCIENCE IN THE MODERN WORLD
}

TN a paper entitled "The Task before Us", read 1 before the American Academy of Arts and Sciences at Boston on April 14*, Dr. P. W. Bridgman examined the philosophy of the founding fathers of American democracy in the light of the scientific thought of this century. He suggested that we have forgotten to regard democracy as a growing thing, evolving to meet our changing conceptions of ourselves and our place in Nature. Anti-intellectualism, he said, might be a symptom of something more deep-seated, and the emphasis on a return to humanistic attitudes requires a revitalization of the humanities themselves in the light of our recent intellectual experiences. We need to assimilate into our whole intellectual outlook, and in particular into our relation to social problems, the lessons implicit in scientific experience. Considering first the changes in intellectual attitude forced on us by such experience, Dr. Bridgman said that a necessary mark of a liberally educated man is the realization that our thinking and intellectual processes in general cannot be taken for granted. When we think, we use intellectual tools, and these tools have properties and limitations. In particular, recent experience shows that when we push the application of many of our concepts into new fields, limitations appear which we could not have anticipated from anything in our former more limited common-sense experience. We have now come to expect that a concept inherited from our ancestors will not be applicable when pushed into fields hitherto unentered. Analogy suggests that the presumption is that such concepts as human rights or duties or responsibilities require modification when the environment in which they $\operatorname{aros} \theta$ is altered, as it now is, by technological advances that bring all men over the whole world into immediate mutal relations.

Dr. Bridgman suggested that it is not a common idea that there are still regions in which the man of science is groping his way and knows that he has not yet found the answers. Failure to realize this is one reason for the impatience of people with the scientific

* The Task before Us. By P. W. Bridgman. Proc. Amer. Acad. Arts Sci., 83, No. 3, ii $+95-112$ (1954). 50 cents. point of view and for the urge to return to a moro humanistic outlook. Among such unsolved problems, Dr. Bridgman gave as examples that of the 'observer' in quantum physies and the growing concern with the basic problem of what sort of thing a brain is. One of the results which is beginning to emerge from cybernetics is a realization of the extent to which our conscious activities have to be selected from the overwhelming number of potentialities. 'The problem becomes not to find the absolute truth but to find how to do the best we can with what we have. Moreover, in psychology the new approach to the nature of perception is forcing on us the simple realization that all our conscious thinking is done in terms of perceptions, and we are now asking whether in the domain of ordinary experience the mould of space and time into which perception pours our world is a good mould. Dr. Bridgman believes that our task is to-find the present status, in the light of all the insights now available to us, of such fundamental concepts as human rights, freedom, equality, duty and justice, and in the light of these insights to strengthen if possible, or to revise if necessary, the conceptual foundation of our social and political system. 'This task will demand a long campaign of education and the slow development of new intellectual techniques by a process involving much trial and error.

Reviewing more concrete aspects of the situation, Dr. Bridgman believes that analysis of the processes in a democratic society will in this way lead us to a society in which tho relation between society and the individual is based on mutual advantage and service. Only exceptionally will it involve honouring minimum claims on the community whether or not any return is made; but it will also involve a revision in the philosophy underlying the system of taxation. Finally, it will place emphasis on two virtues : the repugnance of the individual to exercise force against his neighbour for his own advantage, and the imagination that can sense the significance of the simple underlying processes and relations so easily lost to sight under the complexities of modern lifeor, in other words, intelligence.

\section{THE OIL INDUSTRY}

$\mathrm{T}$ HE oil industry is one which could be said to be less than a hundred years old, or more than two thousand.

It seems probable that it was an ingenious Chinaman who first drilled a hole into the earth's surface. He was in search of salt water and natural gas which he could use as the fuel to evaporate the water to yield salt. In the process he or his successors at times bored down to three thousand feet and incidentally struck oil. They had no use for the oil except as a lubricant (Esso Magazine, 3, No. 11; Spring, 1954).

The rig these Chinese devised is basically not unlike the cable rig used to-day; it sometimes took them ten years to drill a deep hole with their rigs.

Drake used the cable rig method when drilling the world's first commercial oil well in 1859. It was fortunate that he made his attempt in Pennsylvania rather than in Texas, because when the drillers got to
Texas they encountered softer rock formations in which the simple cable rig was useless; the sides of the holes caved in as fast as the bits pounded through. As a result the rotary rig came into being; with this a hole is drilled through rock instead of being pounded through. A length of piping with a 'bit' on its end is gripped and rotated like a carpenter's drill. Mud, forced down the pipe, comes to the surface again in the space between pipe and hole, thus sealing off loose formations as the hole is drilled and bringing the cuttings to the surface. Two-thirds of wells sunk to-day are drilled by rotary rigs.

The drill pipe has greater precision than the cable for deeper holes; it also goes down straighter. This is important to-day, when wells are being drilled deeper every year.

During the Second World War there was not enough easily located shallow oil to keep industry and machines operating. New sources had to be 
found. The drillers' bits now probed the rock formations of the Eocene and Oligocene ages; soon wells were being drilled to $12,000 \mathrm{ft}$. To-day, in the United States alone, ninety-seven wells are being operated at depths below 15,000 ft., of which twentytwo were drilled last year.

Difficulties increase, and costs multiply, with greater depths. (A 15,000-ft. well is three times as expensive as one of $10,000 \mathrm{ft}$. It may cost anything up to $£ 400,000$ to drill.) The strains imposed on rigs at a depth of two or three miles are vastly greater than with more shallow wells. Derricks have to be of much heavier construction to take the weight of the drill pipe and to hoist it up out of the hole. The heat at $15,000 \mathrm{ft}$. seriously interferes with the effectiveness of the normal drilling muds. Bits wear out more quickly owing to the greater density and hardness of the deep rock formations. Pipe that is fully adequate to drill to $5,000 \mathrm{ft}$. will twist at double that depth and drill crooked holes. The recent use of diamond bits for deep-hole drilling has eased the problem.

'The world's deepest well had reached 21,482 ft. a little time ago when it was halted by a core stuck at the bottom and the drill pipe stuck at $12,000 \mathrm{ft}$. The core will reveal whether the well has reached formations of the Oligocene age. If it is still in shales of the lower Myocene age, drilling may be discontinued-with no oil found.

One of the most interesting of recent developments has been the adoption of directional drilling, the process whereby the direction taken by the bit can be changed while drilling is in progress-or the well can be drilled from the start at a chosen angle from the vertical. By this technique it is possible to deflect a hole from an unproductive to a productive part of an area and so save the time and cost of drilling again from the top ; the hole can be deflected around particularly hard and difficult underground formations; a fire at a well can be brought under control by drilling a slanted relief well into it; by the same means one can drill under the sea from dry land.

The angle of drift is effected by means of a tool called a whipstock; this is a 'cone' which is lowered into the hole base first with its apex pointing upwards. A drilling bit will always follow the line of least resistance and, when it encounters the apex of the cone, it is naturally deflected from its vertical path at an angle, the angle being dictated by the shape of the whipstock used. Normally, the full angle to which it is intended to deflect a hole is made by a series of whipstock operations, the drift being increased $2-3^{\circ}$ every hundred feet until an average angle of $10-45^{\circ}$ has been obtained. Directional drilling programmes have been known to achieve a drift of $80^{\circ}$ to a vertical depth of $8,000 \mathrm{ft}$.

Drilling practice is never static. The direction of advance has been and will be towards the automatic rig. The most difficult task has always been the racking of the drill pipe as it comes out of the hole in sections of ninety feet or more. Steel arms at various heights have now been evolved to do this automatically. Unscrewing the pipe joints also taxes the strength of the operators. Chains on winches havo been used for twisting the pipe, but powerdriven 'tongs' have done this by the push of a lever. To speed drilling a jet bit has been produced.

The greatest depth at which oil has been discovered is $17,895 \mathrm{ft}$. It is hoped that much more will be discovered below $20,000 \mathrm{ft}$.

\section{SELECTION OF SUPERVISORS}

IN June 1948, the National Institute of Industrial Psychology's Foremanship Research Group conducted an experimental selection procedure in a large heavy-engineering works in Scotland. Two different selections for promotion to supervisory positions were made from a field of 110 candidates, obtained by advertisement within the firm. The first selection was made by management by their customary method of review and nomination; in the second, from the same field, systematic methods were used, including biographical history sheets, recommendation forms, intelligence tests, interviews, group discussion sessions, and a final selection panel. The latter procedure was carried out by members of the management with the advice and assistance of a member of the staff of the National Institute of Industrial Psychology.

After two years a check was made and gradings by the selection panel for the $\mathbf{4 4}$ men regarded as worth serious consideration for promotion correlated $0.68 \pm 0.08$ with assessments made on these men by their managers two years after the original selection. This was an encouraging result in comparison with the poor prediction, $0 \cdot 23 \pm 0 \cdot 14$, obtained by management's normal procedure. Another check has now been made by J. D. Handyside and D. C. Duncan some four years and five months after the original selection experiment*.

Two criteria were available against which to assess the efficiency of selection : first, ratings by managers who were in a position to assess the performance of the men concerned; and, secondly, whether the men had been promoted twice, once, or not at all during the four and a half year period.

Management's customary method of selection consisted of short interviews by the candidates' managers and discussion among managers who could be expected to know the men reasonably well. The results of the experimental evaluation of this method indicated that it was defective to a startling degree.

It appears from this experiment that a combination of existing, fairly elementary, selection techniques permits prediction of supervisory success - as measured by management criteria--just about as well as the uncertainties of the criteria allow. Nevertheless, there is a need to improve the economic efficiency of the selection methods.

* Occupational Psychology, 28, No. 1; January 1954.

\section{GULMARG RESEARCH OBSERVATORY}

\author{
By Prof. P. S. GILL
}

Director of the Observatory and Head of the Department of Physics, Aligarh Muslim University

$\mathrm{W}$ ITH the development of the subject of cosmic radiation the need for stations at various heights and in different parts of the world has become increasingly important. Previously, the high-altitude research stations were used for astronomical, astrophysical, meteorological and terrestrial magnetic measurements; but during recent years these stations have become mainly associated with the work in cosmic rays. In the Americas, a number of highaltitude research stations have been established through the efforts of cosmic-ray investigators, some of which-Mount Evans, Echo Lake, Climax, Mexico 